\title{
First Results of the Free Flap Transfer for the Head and Neck Reconstruction: The Public Hospital Experience
}

\author{
Andrey Karpenko, Laslo Roman, Natalia Chumanikhina, Igor Kostyuk, Ramil Sibgatullin, Elena Belova \\ Nadezhda Evdokimova, Dilavar Dzhalilov
}

\begin{abstract}
The aim of the study is to assess our first results with the free flap transfer. Since October 2006 through April 2012, 58 operations were performed. The upper digestive tract was reconstructed in 46 cases, the soft tissues and skin of the head and neck region - in 12 cases. The primary plasty was performed in all but two cases. E ighteen first cases were performed with 2. 5 and $4 x$ binocular loupes magnification only. The operating microscope was used in 40 cases. Fourty-two radial forearm fasciocutaneous flaps, five latissimus dorsi musculocutaneous flaps, nine anterolateral thigh flaps, one scapular osteocutaneous flap were used with the single case of the visceral flapthe jejunal flap. Death in early postoperative period occurred once. Complete flap loss occurred six times. Five radial and one latissimus dorsi free flaps were lost. The arterial thrombosis is considered as the primary cause of failure in one case, venous thrombosis - in two cases, postoperative infection-in one case with remaining two cases of the unknown primary cause of failure. There were three cases of the revision surgery with the attempts to reperform venous anastomosis, one of them was successful. The overall success rate in this series is $87.9 \%$. Most of the failures occurred early in the series. The main cause of such a low rate of the success is a lack of experience. Even in a so small number of patients the results significantly improved from 72.2 to $94.4 \%$.
\end{abstract}

Keywords: Head and neck surgery, Reconstruction, F ree tissue transfer.

How to cite this article: Karpenko A, R oman L, Chumanikhina N, Kostyuk I, Sibgatullin R, Belova E, Evdokimova N, Dzhalilov D. First Results of the Free Flap Transfer for the Head and Neck Reconstruction: The Public Hospital Experience. Int J Head Neck Surg 2012;3(2):66-72.

\section{Source of support $\mathrm{Nil}$}

Conflict of interest: None declared

\section{INTRODUCTION}

The surgical defects of the head and neck area can be reconstructed by many techniques. The local, pedicled and free flaps form the so called reconstructive ladder. A lthough most technically demanding the free flap transfer has become the method of choice for the reconstruction of the head and neck defects after the ablative tumor surgery due to its high reliability and better function. ${ }^{1-5}$ Those better outcomes are well-documented in medical literature. ${ }^{6,7}$ Increased awareness of that fact made us to switch our reconstructive efforts from the pedicled to freeflaps. In most reports nowadays, the success rate with the technique of microvascular flap transfer is well over $90 \%^{1,2,5}$ and even approaches $100 \%{ }^{3,4} \mathrm{~V}$ ast majority of those reports originate from the clinics with decades of experience in this difficult field of surgery. N evertheless, the mastering of the technique of the free tissue transfer by the novice surgeon and establishing the practice of the microsurgery can be quite challenging. We present our initial experience that is characterized by the following. All operations were performed in the public hospital. Neither member of the surgical team had had any previous personal clinical experience with the free flap transfer. So, this series represents some kind of the learning curve of the microvascular flap transfer technique for the single surgical team over a period of more than 5 years.

\section{METHODS}

The medical charts of 57 patients treated surgically with the use of free flaps since O ctober 2006 through A pril 2012 were reviewed. One patient was operated twice, so the total number of operations was 58. There were 40 male and 17 female patients aged from 46 to 78 years (Table 1 ).

The reconstruction was primary in all but 2 cases. In 57 cases free flaps were used for the reconstruction of the defects after the ablative tumor surgery. The remainder case of the cicatricial pharyngeal stenosis after the laryngectomy was the indication in one patient. The recipient sites for free flaps were: The oral cavity (39 cases), oropharynx (five cases), hypopharynx (two cases), skin and soft tissues defects of the head and neck (12 cases, Table 2).

Squamous cell carcinoma was the most frequent type of cancer- 46 cases $(79.3 \%$, Table 3$)$.

Table 1: Patients characteristics

\begin{tabular}{ll}
\hline Total no. & $57(\%)$ \\
\hline Male & $40(70.2)$ \\
Female & $17(29.8)$ \\
Mean age & $56.9(46-78)$ \\
Smoking history & $47(82.5)$ \\
\hline
\end{tabular}

Table 2: Recipient sites

\begin{tabular}{lc}
\hline Site & No. $(\%)$ \\
\hline Oral cavity & $39(67.3)$ \\
Oropharynx & $5(8.6)$ \\
Hypopharynx & $2(3.4)$ \\
Skin & $12(20.7)$ \\
\hline Total & $58(100)$ \\
\hline
\end{tabular}


First Results of the Free Flap Transfer for the Head and Neck Reconstruction: The Public Hospital Experience

Eleven patients were operated due to recurrences. Ten of them were irradiated previously to a total dose of 60 to $72 \mathrm{~Gy}$. A mong 46 primary patients the majority presented in advanced stage disease (41 patients, $87.2 \%$, Table 4).

The resection of the primary tumor was accompanied by the neck dissection in 47 cases. The latter was bilateral in 11 patients. The most frequent type of the dissection was the modified radical one (40 cases, Table 5).

There were 18 marginal and 18 segmental mandibulectomies performed along with the excision of the primary. B one defects were reconstructed only twice (one bone flap and one reconstruction plate with the soft tissue covering).

Table 3: Pathology

\begin{tabular}{lc}
\hline Pathology & No. of cases (\%) \\
\hline Squamous cell carcinoma & $46(79.4)$ \\
Skin basal squamous cell carcinoma & $10(17.2)$ \\
Skin melanoma & $1(1.7)$ \\
Skin adnexal carcinoma & $1(1.7)$ \\
\hline Total & $58(100)$ \\
\hline
\end{tabular}

Table 4: TNM stage of 46 primary patients

\begin{tabular}{lcccc}
\hline T/N & N0 & N1 & N2 & Total \\
\hline T2 & 5 & 0 & 0 & 5 \\
T3 & 8 & 1 & 4 & 13 \\
T4 & 8 & 7 & 13 & 28 \\
\hline Total & 21 & 8 & 17 & 46 \\
\hline
\end{tabular}

Table 5: Types of neck dissection

\begin{tabular}{lc}
\hline Type & No. of cases \\
\hline Modified radical neck dissection & 40 \\
Selective neck dissection & 16 \\
Radical neck dissection & 2 \\
\hline Total & 58 \\
\hline
\end{tabular}

Table 6: Types of flaps used

\begin{tabular}{lr}
\hline Type of flap & No. (\%) \\
\hline Radial forearm & $42(72.5)$ \\
Latissimus dorsi & $5(8.6)$ \\
J ejunal & $1(1.7)$ \\
Anterolateral thigh & $9(15.5)$ \\
Scapular osteocutaneous & $1(1.7)$ \\
\hline Total & $58(100)$ \\
\hline
\end{tabular}

There were 42 radial forearm fasciocutaneous, five latissimus dorsi musculocutaneous, one jejunal, nine anterolateral thigh and one scapular osteocutaneous free flaps (Table 6). B oth latter flaps were started to be used only recently.

The reconstructive procedures were performed by the head and neck surgeon trained in the microvascular surgery. The facial artery was the most frequently used recipient artery (49 cases). One of the tributaries of the internal jugular vein (most frequently - the facial vein) was used for the venous anastomosis in 47 cases. M ost vascular anastomoses were performed in end-to-end fashion, except as indicated in Table 7.

The binocular loupes with 2.5 and $4 \times$ magnification were used as the only optical aid in the first 18 cases, further in this series (from the case no.19) the operating microscope was used. The operation time ranged from 6 to 12 hours (mean time, $8 \mathrm{~h} 35 \mathrm{~min}$ ). The flaps were monitored by the close observation, temperature control and prick test.

\section{RESULTS}

There was one postoperative death $(1.7 \%$, case no. 6$)$ on day 2 after the operation due to the pulmonary embolism. The postoperative period in this case was complicated by the postoperative bleeding and venous thrombosis of the flap pedicle on the Ist postoperative day. During revision surgery the venous anatomosis was successfully reperformed. The operation time of two sessions in this case exceeded 8 hours ( 9 h 55 min). Despite the standard intensive and anticoagulant therapy the death ensued the next day after the revision surgery. The total flap loss occurred six times. five radial forearm and one latissimus dorsi flaps were lost (Table 8).

Two flaps were lost due to the venous thrombosis, onedue to arterial thrombosis. The severe postoperative wound infection caused the flap necrosis in one patient. The primary cause of failure could not be determined in the remaining two cases. The pectoralis major myocutaneous flap was the most frequently used as the secondary reconstruction option (Table 8.)

Revision surgery due to the venous thrombosis in the early postoperative period was attempted three times. One of them was successful (Figs $1 \mathrm{~A}$ and B). In another case,

Table 7: Recipient vessels

\begin{tabular}{lclc}
\hline Arteries & No. $(\%)$ & Veins & No.(\%) \\
\hline Facial & $49(84.5)$ & Facial (or other tributary of internal jugular) & $47(81.0)$ \\
External carotid & $5(8.6)$ & External jugular & $4(6.9)$ \\
Lingual & $3(5.2)$ & Internal jugular (end-to-side) & $7(12.1)$ \\
Superior thyroid & $1(1.7)$ & & $58(100)$ \\
\hline Total & $58(100)$ & Total & \\
\hline
\end{tabular}




\begin{tabular}{clcll} 
& & \multicolumn{2}{c}{ Table 8: Total flap losses } \\
\hline Case no. & Flap & Postop day & Cause & Secondary reconstruction \\
\hline 4 & Radial forearm & 5 & Unknown & Local flaps \\
12 & Radial forearm & 14 & Unknown & Pectoralis major \\
15 & Latissimus dorsi & 6 & Arterial thrombosis & Pectoralis major \\
16 & Radial forearm & 2 & Venous thrombosis & Pectoralis major \\
28 & Radial forearm & 4 & Venous thrombosis & Pectoralis major \\
32 & Radial forearm & 10 & Infection & Combined pectoralis major \\
& & & & and bilateral deltopectoral \\
\end{tabular}

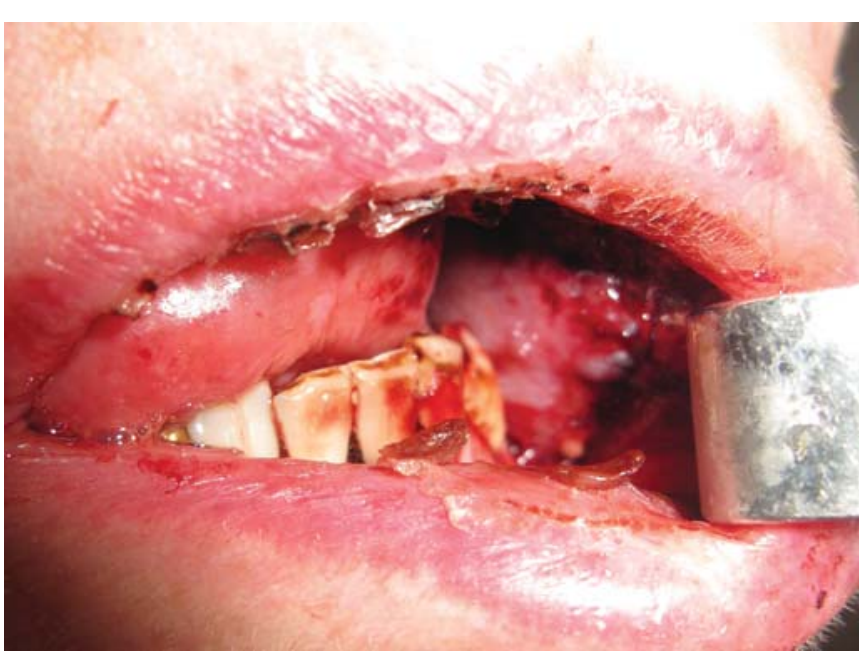

Fig. 1A: Radial forearm flap used for the reconstruction of the buccal mucosa. Early signs of the venous thrombosis of the flap

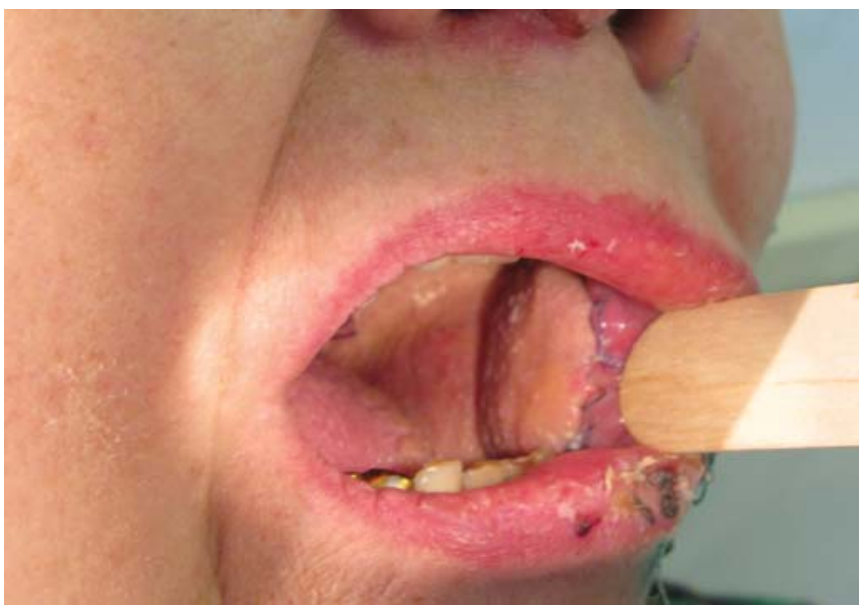

Fig. 1B: Flap was successfully salvaged after reanastomosis

the problems were recognized too late (Fig. 2). A fter reperforming the venous anastomosis the appearance of the flap was somewhat improved, but ultimately it was lost the same day. The remaining case was cited above (case no. 6), so the success rate of the revision surgery was $33.3 \%$ (1 out of 3 flaps was salvaged).

The postoperative bleeding occurred five times $(8.6 \%)$. The overall incidence of the returning of the patient to the operation room was $17.2 \%$ (10 cases).

Other surgical complications at the recipient site were minor (Table 9). The wound dehiscence and seroma

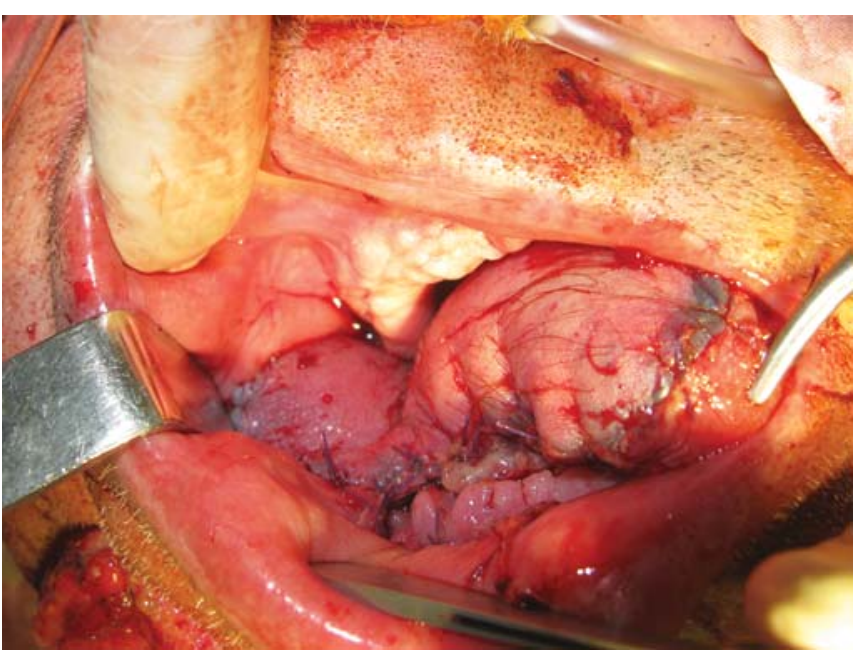

Fig. 2: Late signs of the venous thrombosis of the radial forearm flap. The flap was lost

\begin{tabular}{lc}
\multicolumn{2}{c}{ Table 9: Minor complications } \\
\hline Complication & No. of cases \\
\hline Partial flap necrosis & 3 \\
Wound dehiscence & 8 \\
Infection & 4 \\
Salivary fistula & 4 \\
Seroma & 8 \\
\hline
\end{tabular}

formation were the most frequent. All those complications were managed in conservative manner. Four salivary fistulas closed spontaneously with such conservative treatment.

Considering one postoperative death as a failure the ultimate success rate in this series is $87.9 \%$. Some clinical examples are depicted on Figures 3 to 6 .

\section{DISCUSSION}

The free flap transfer has become the routine practice in many head and neck surgery departments. Presently, the reported success rates always well exceed $90 \% .^{1-5}$ From this point of view the reasonable question of how to treat of such a low rate of this series ensues. The first issue is the optical aid. M ost of our failures (4 of 6) occurred when the binocular loupes were used. It is indeed not very popular device for the magnification, but the literature review reveals excellent results obtained by many surgeons. Shenaq et al ${ }^{8}$ reported $98.5 \%$ success rate in 199 patient, using 5.5x 


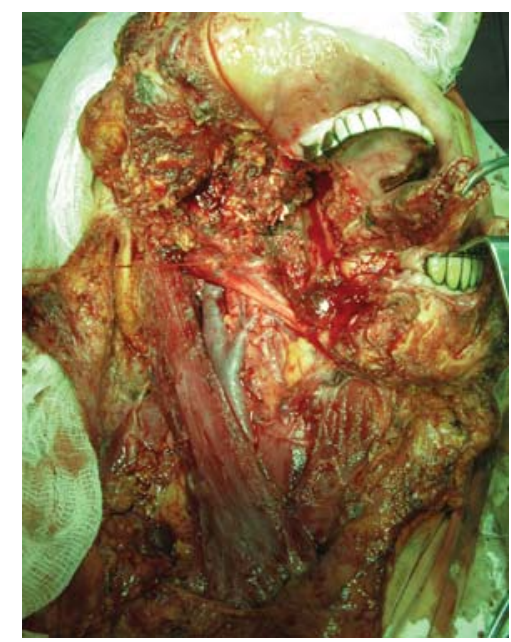

Fig. 3A: Operative wound after the right modified radical neck dissection and excision of the primary. Defect: The mandible angle and ramus, left tonsil, partial defect of the tongue, subtotal defect of the soft palate

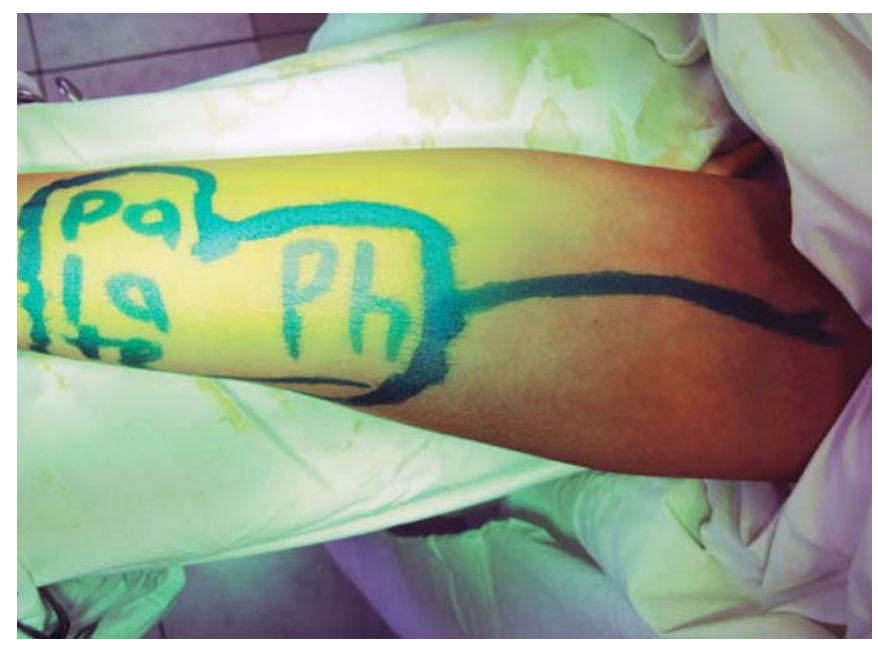

Fig. 3B: Flap design. Palatal portion of the flap was folded on itself to form both anterior and posterior epithelial linings of the neopalate

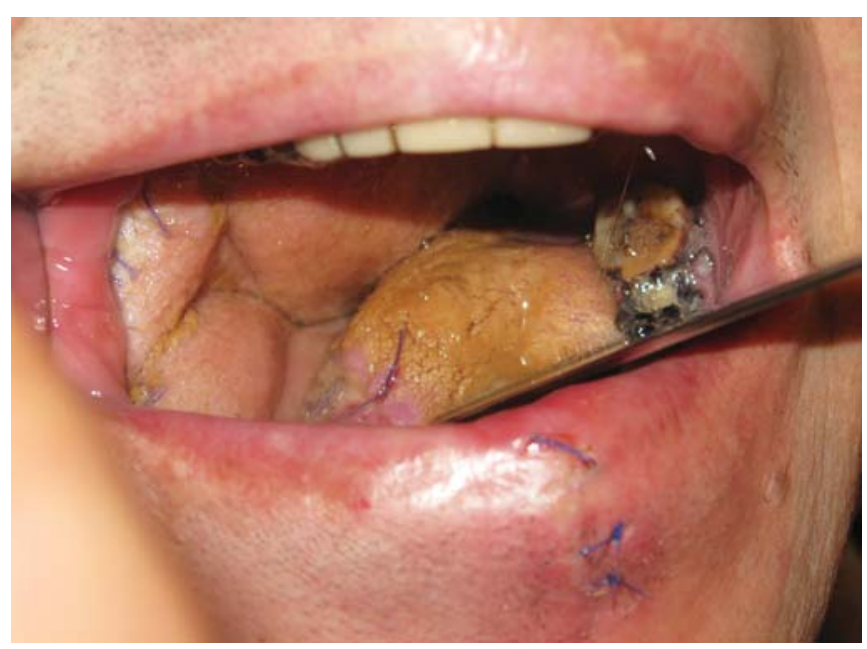

Fig. 3C: Stomatoscopy 1 month postoperatively

loupes. A nother surgical team ${ }^{9}$ compared results obtained with the microscope and $3.5 \times$ magnification binocular loupes assisted free tissue transfer. The results in both groups

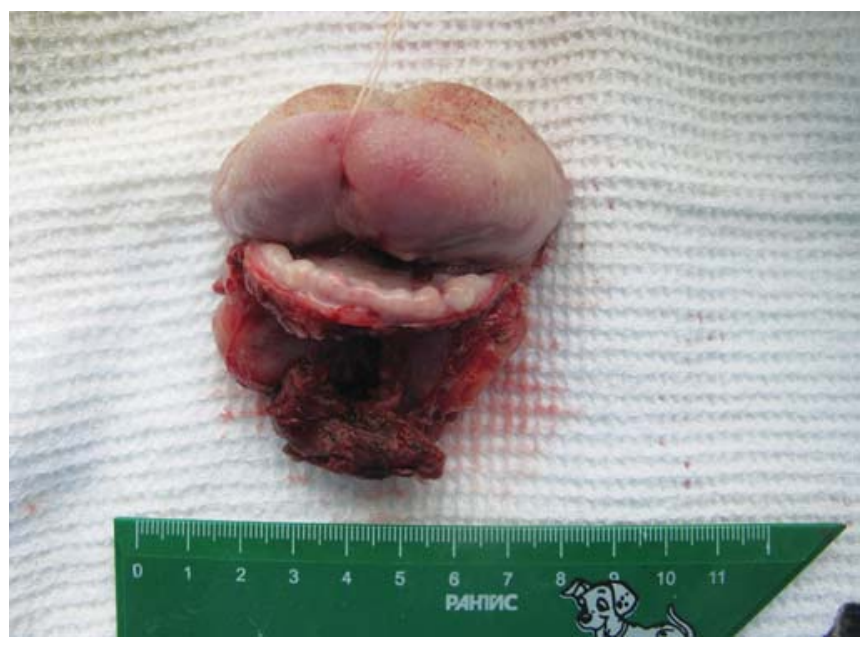

Fig. 4A: Operative specimen. Defect: Anterior mobile tongue, floor of the mouth

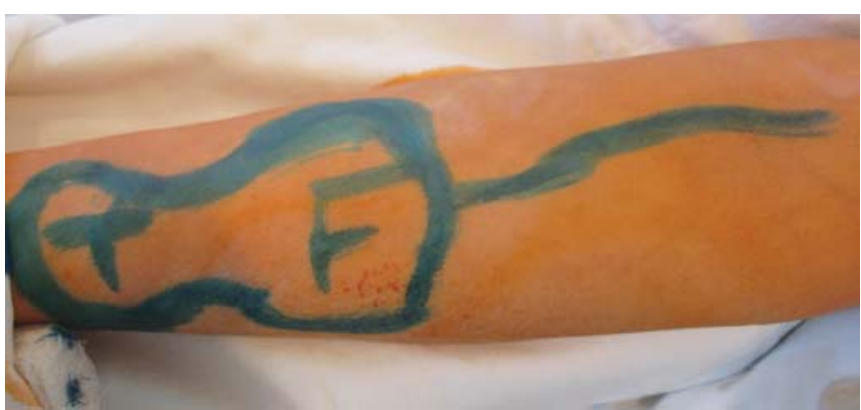

Fig. 4B: Radial forearm flap design with tongue and floor of the mouth portions. The flap was partially folded on itself to provide sufficient height of the neotongue

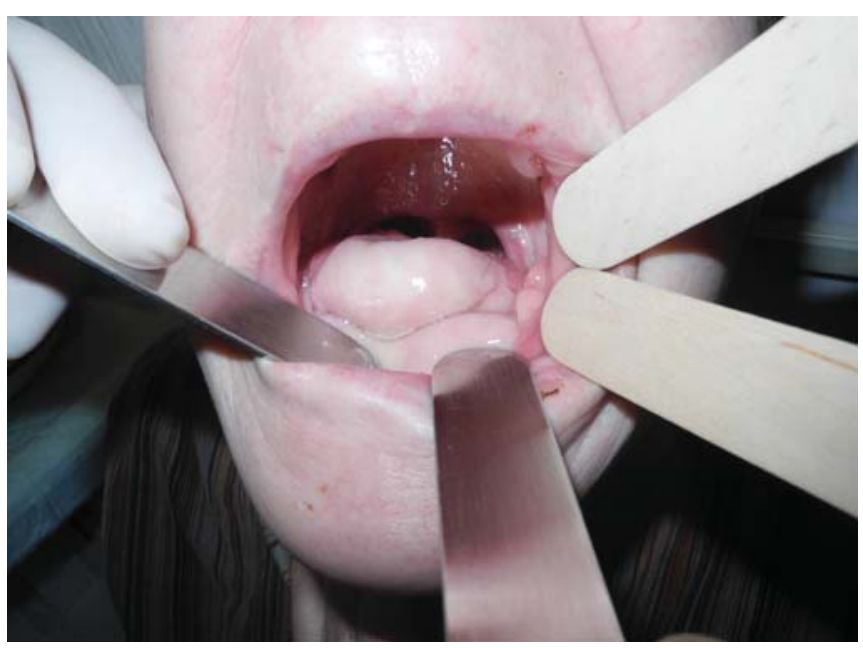

Fig. 4C: Stomatoscopy 3 months postoperatively

were similar and successful in more than $99 \%$ of cases. A lthough these authors emphasized that the early cases were operated only with the microscope. Similar conclusions can be drawn from the article by Ross et al. ${ }^{10}$ They concluded that the method of the optical aid is the issue of the personal preference of the experienced microsurgeon. So, the loupes, as the method of magnification, is not the most important reason for the failure. The issue of the much more 


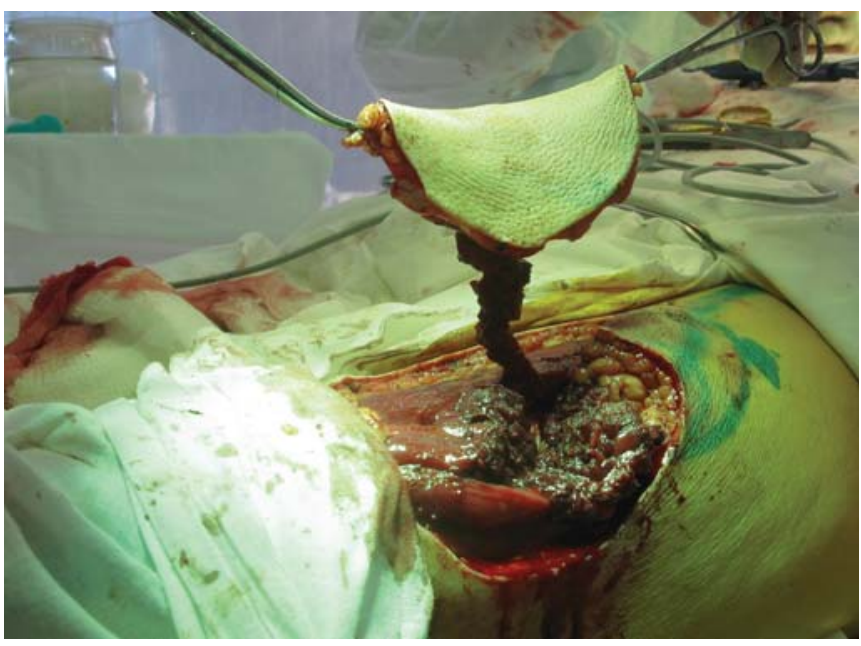

Fig. 5A: Raised anterolateral thigh flap for the reconstruction of the anterior oral cavity

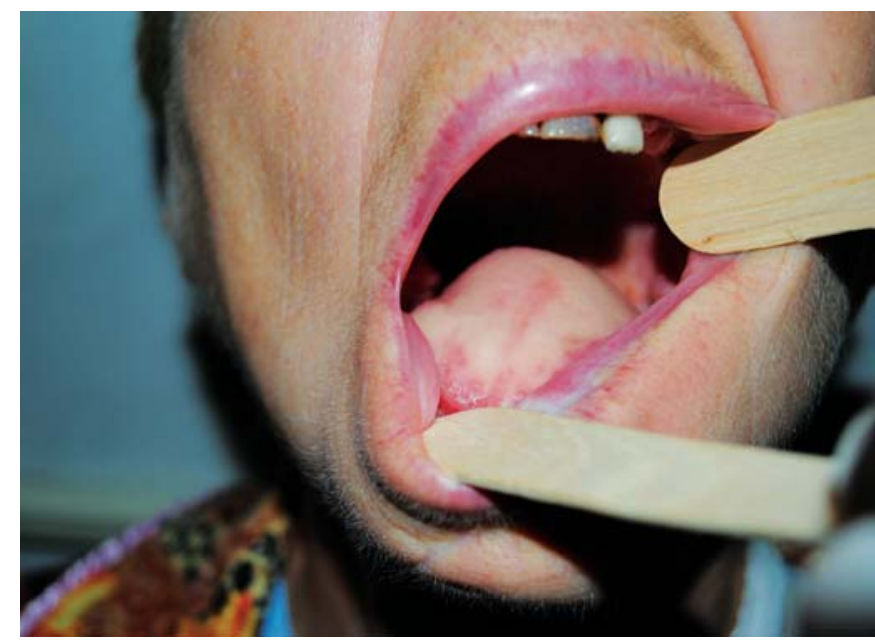

Fig. 5B: Postoperative stomatoscopy

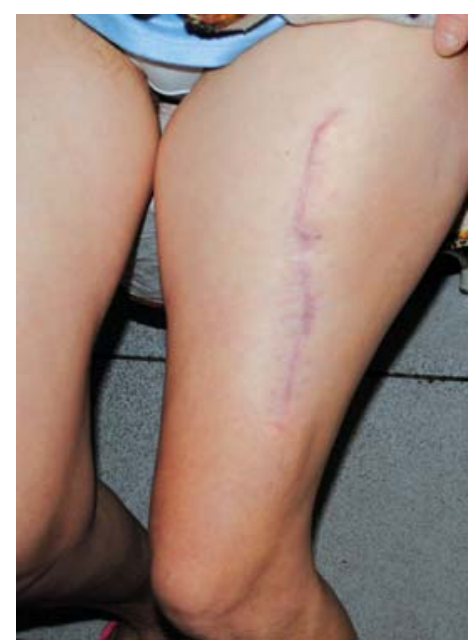

Fig. 5C: Donor site (left thigh)

importance is the clinical experience. Almost all reports about the free tissue transfer in the medical literature nowadays are from the clinics with decades of experience in this highly demanding field of surgery, where the art,

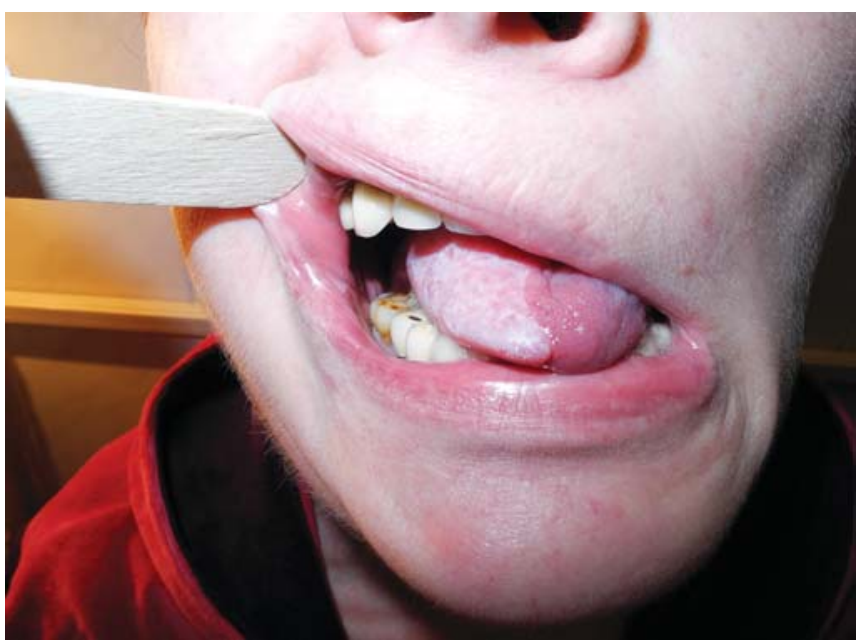

Fig. 6A: Hemiglossectomy defect reconstructed with radial forearm free flap

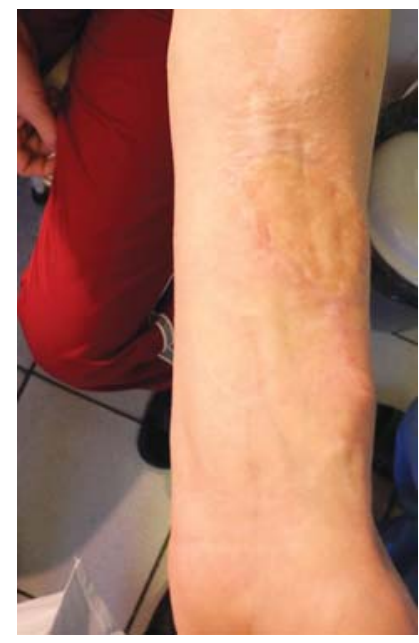

Fig. 6B: Donor site (left forearm)

technique and knowledge are transmitted from the generation to generation of the microvascular surgeons. Such situation does not exist everywhere. There do exist clinics where the surgeons have to embark with the free flaps themselves without any clinical experience- the situation, which took place in the developed countries 20 to 30 years ago. It is quite difficult now to retrieve from the medical literature the results of the free flap transfer of that era of the microsurgery. Davies ${ }^{11}$ summarized the experience of microsurgeons in 1982. The reported success rate was $89 \%$. M ost comprehensive and illustrative review was performed by K houri ${ }^{12}$, who analyzed results obtained by nine microsurgeons. The early results in all hands were usually much worse (Table 10). With increasing number of cases the success rate raised from 72 to $91 \%$ to 96 to $97 \%$.

Similar results were obtained by the present authors. Over the 5 years period with the more frequently performed operations the success rate has raised from 72.2 to $95 \%$ (Table 10). Our data confirmed the statement of K houri ${ }^{12}$ 
First Results of the Free Flap Transfer for the Head and Neck Reconstruction: The Public Hospital Experience

Table 10: Free flap success rates (From Khouri RK, 1992)

\begin{tabular}{llr}
\hline Author & Experience & Success rate \\
\hline Serafin (1980) & First 25 cases & $72 \%$ \\
& Last 25 cases & $96 \%$ \\
Godina (1986) & First 100 cases & $74 \%$ \\
& Last 100 cases & $96 \%$ \\
Harashina (1988) & First 3 years & $75 \%$ \\
& Last 5 years & $97 \%$ \\
Buncke (1989) & First 3 years & $83 \%$ \\
& Last 3 years & $97 \%$ \\
Shaw (1989) & First 100 cases & $91 \%$ \\
& Last 100 cases & $97 \%$ \\
Present report & First 2 years: 18 cases, & \\
& 1 death, 4 flap losses & $72.2 \%$ \\
& Last 3 years: 40 cases, & $95.0 \%$ \\
\hline
\end{tabular}

that the clinical experience is the single most critical factor related to improved success rates. The standard microvascular training consists of the limited number of lectures, attendance of the operating room, ICU departments, observing patients before and after surgery and, of course, training of the basic microsurgical techniques in the microvascular laboratory, most often in the rat model. The importance of the latter can not be overemphasized. ${ }^{15-17} \mathrm{~B}$ ut the excellent results in the rat model in the comfortable laboratory conditions does not necessarily transform into those in the clinical setting, at least in our practice. The success of the microvascular free tissue transfer depends on many factors: The adequate patient selection (we believe that the death of the patient was partly due to our underestimation of his comorbidity), precise and delicate operative technique, adequate geometry and length of the pedicle, proper choice of the recipient vessels, close monitoring to name a few. It is very difficult to obtain this knowledge in the laboratory or time-limited attendance of the operating room. The practice is the only way to gain the deep understanding of those factors. Our data confirm that the experience is the main determinant of the success in the free tissue transfer and the initial results could be somew hat less than optimal.

\section{REFERENCES}

1. Eckardt A, M eyer A, L aas U, H ausamen J-E. R econstruction of defects in the head and neck with free flaps: 20 years experience. BrJ Oral Maxillofac Surg 2007;45:11-15.

2. Pohlenz P, B lessmann M, Blake F, Li L, Schmelzle R, H eiland $M$. Outcome and complications of 540 microvascular free flaps: The Hamburg experience. Clin Oral Invest 2007;11:89-92

3. Suh JD, Sercarz JA, A bemayor E, C al cattera TC, R awnsley JD, A lam D, B lackwell KE. A nalysis of outcome and complications in 400 cases of microvascular head and neck reconstruction. A rch Otolaryngol Head N eck Surg 2004;30:962-66.
4. Alan Turner MJ, Smith WP. Double venous anastomosis for the radial artery forearm flap. I mproving success and minimizing morbidity. J Craniomaxillofac Surg 2009;37:253-57.

5. Bianchi B, Copelli C, Ferrari S, Ferri A, Sesenna E. Free flaps: Outcomes and complications in head and neck reconstructions. J Craniomaxillofac Surg 2009;37:438-42.

6. Chepeha D, A nnich G, Pynnonen M, Beck J, Wolf G, Teknos $T$, et al. Pectoralis major myocutaneous flap vs revascularized free tissue transfer. A rch Otolaryngol Head N eck Surg 2004;130: 181-86.

7. M cCrory A, M agnuson JS. F ree tissue transfer versus pedicled flap in head and neck reconstruction. Laryngoscope 2002;112:2161-65.

8. Shenaq S, K lebuc M , V argo D. F ree-tissue transfer with the aid of loupe magnification: Experience with 251 procedures. Plast Reconstr Surg 1995;95:261-69.

9. Serletti J M , D euber M A, Guidera PM , R eading G, Herrera HR, Reale VF, et al. Comparison of the operating microscope and loupes for free microvascular tissue transfer. Plast R econstr Surg 1995; 95:270-76.

10. Ross D, A riyan S, Restifo R, Sasaki C. U se of the operating microscope and loupes for head and neck free microvascular tissue transfer. A retrospective comparison. A rch Otolaryngol Head N eck Surg 2003;129:189-93.

11. Davies D. A world survey of anticoagulation practice in clinical microvascular surgery. B I J Plast Surg 1982;35:96-99.

12. Khouri R. Avoiding free flap failure. Clin Plast Surg 1992;19:773-81.

13. Serafin D. M icrosurgery: Past, Present and future. Plast R econstr Surg 1980;66:781-85.

14. Harashina T. A nalysis of 200 free flaps. Br J Plast Surg 1988;41:33-36.

15. Studinger R, B radford M, J ackson I. M icrosurgical training: Is it adequate for the operating room? Eur J Plast Surg 2005;28: 91-93.

16. Hui K, Zhang F, Shaw W, Kryger Z, Piccolo N, Harper A, Lineaweawer $W$. Learning curve of microvascular venous anastomois: A never ending struggle? Microsurgery 2000;20: 22-24.

17. $M$ artins $1 P, M$ ontero $E$. B asic microsurgery training. Comments and proposal. A cta Cirurgica B rasileira 2007;22:79-81.

\section{ABOUT THE AUTHORS}

\section{Andrey Karpenko (Corresponding Author)}

Department of Head and N eck, L eningrad R egional Oncologic Dispensary Saint-Petersburg, Russian Federation, e-mail: andrei_karpenko@ mail.ru

\section{Laslo Roman}

Department of Head and Neck, Leningrad Regional Oncologic Dispensary, Saint-Petersburg, Russian Federation

\section{Natalia Chumanikhina}

Department of Head and Neck, Leningrad Regional Oncologic Dispensary, Saint-Petersburg, Russian Federation

\section{Igor Kostyuk}

Department of Head and Neck, Leningrad Regional Oncologic Dispensary, Saint-Petersburg, Russian Federation 


\section{Ramil Sibgatullin}

Department of Head and Neck, L eningrad Regional Oncologic Dispensary, Saint-Petersburg, Russian Federation

\section{Elena Belova}

Department of Head and Neck, Leningrad Regional Oncologic Dispensary, Saint-Petersburg, Russian Federation

\section{Nadezhda Evdokimova}

Department of Head and Neck, Leningrad Regional Oncologic Dispensary, Saint-Petersburg, Russian Federation

\section{Dilavar Dzhalilov}

Department of Head and Neck, Leningrad Regional Oncologic Dispensary, Saint-Petersburg, Russian Federation 